\title{
Analgesic Nephropathy due to Diclofenac in a 24-year-old Indian Male Patient: A Case Report
}

\author{
Sukant Pandit*, Vishal Mishra, Chetna Desai \\ Department of Pharmacology B.J. Medical College Ahmedabad, Gujarat, INDIA.
}

\begin{abstract}
Analgesics are commonly prescribed first line agent for the treatment of rheumatological disorders like rheumatoid arthritis and ankylosing spondylitis. Renal toxicities are known adverse reactions of analgesics, however, acute onset renal injury due to analgesics in rheumatological disorders is not currently known. Here we describe a case of a 24-yearold Indian male patient who was diagnosed with ankylosing spondylitis three years back and was prescribed tablet Diclofenac $150 \mathrm{mg}$ in three divided doses per day. The patient presented with breathlessness, pedal edema and decreased urine output on $24^{\text {th }}$ February 2019. The patient was diagnosed to have bilateral End Stage Renal Disease (ESRD) with small kidneys, pulmonary edema and left ventricular dysfunction using echocardiography. The patient was symptomatically treated and later transferred for renal transplant.

Renal toxicity of analgesics is known but is usually reported after years of
\end{abstract}

exposure. This case is first of the kind of occurrence of ESRD within three years of exposure. This case highlights the need for monitoring in patients who are prescribed analgesics for a long duration especially in patients of rheumatological disorders.

Key words: Diclofenac, Nephropathy, Analgesic, Ankylosing spondylitis, Young.

Correspondence

Dr. Sukant Pandit

$3^{\text {rd }}$ Year Resident, Department of Pharmacology, BJ Medical College, Ahmedabad-380016, Gujarat, INDIA.

Phone: +91-0141-8302557966

Email: sukantpandit1803@gmail.com

DOI: 10.5530/jyp.2020.12.79

\section{BACKGROUND}

Ankylosing spondylitis, an autoimmune disease that affects young males more commonly and is seen in patients with HLA-B27. Non-steroidal anti-inflammatory drugs (NSAIDs) form the first line therapy in the management of ankylosing spondylitis. However, NSAIDs are associated with various adverse effects on long term use. Our case report discusses a rare presentation of acute onset analgesic nephropathy in a young adult male patient.

\section{CASE PRESENTATION}

A 24-year-old Indian male patient presented in the medicine department on $24^{\text {th }}$ February 2019 with breathlessness, pedal edema, decreased urination and reddish discoloration of urine. The patient was asymptomatic 4 years back when he developed low back pain. The pain was insidious in onset, slowly progressive and relieved by walking. The pain was aggravated during morning hours and relieved by exercise and by evening. The patient was treated symptomatically for 1 year with Diclofenac given $150 \mathrm{mg}$ a day in three divided doses. On $11^{\text {th }}$ August 2016 the patient was diagnosed to be having Ankylosing spondylitis with positive HLA B27. The treatment with Diclofenac $150 \mathrm{mg}$ in three divided doses was continued with an exercise regimen.

After admission of the patient in the medicine department on $24^{\text {th }}$ February 2019, routine investigations were conducted. Urine examination showed the presence of blood and protein in a high amount, signifying glomerular injury. Serum creatinine was found to be $16 \mathrm{mg} / \mathrm{dl}$.

Chest $\mathrm{X}$ ray revealed bat-wing appearance signifying pulmonary edema as depicted in Figure 1. USG abdomen revealed smaller size kidney of 69 X 25 mm (Right Kidney) and 51 x 27 mm (Left Kidney) with raised cortical echogenicity and loss of cortico-medullary differentiation. Free fluid was noted in the peritoneal cavity and moderate fluid was noted in the pleural bilaterally. Serum PTH was found to be more than 3 times of the Upper Normal Limit suggesting renal osteodystrophy.

Echocardiography was done on $25^{\text {th }}$ February 2019 revealed LVEF of $35 \%$ with global LV hypokinesia, severe mitral regurgitation and RVSP of $42 \mathrm{~mm} \mathrm{Hg}$ signifying pulmonary arterial hypertension. The patient was diagnosed to be suffering from dilated cardiomyopathy. The patient was treated empirically with Piperacillin-tazobactam, Metronidazole and Azithromycin. Other drugs like heparin, aspirin, clopidogrel, atorvastatin, furosemide, prednisolone, hydroxychloroquine and sevelamer were also prescribed. Emergency hemodialysis was done twice before shifting the patient to the nephrology department with advice for renal transplant.

\section{DISCUSSION}

Ankylosing spondylitis (AS) is a disease affecting the joints and back with initial manifestation is around $2^{\text {nd }}$ decade of life with higher male preponderance. NSAID's are the first line agents in the treatment of AS. Recently it has been found out that AS patients also have renal abnormalities, ${ }^{1}$ most common being renal amyloidosis. ${ }^{2,3}$ Analgesic overuse is notorious for causing serious damage to kidneys by blocking the production of prostaglandins, which play an important role in maintaining homeostasis in kidneys. ${ }^{4}$ In a case series it was found that patients with AS have renal vascular abnormality and patients taking NSAIDs should be regularly monitored as it affects the renal homeostasis. ${ }^{5}$ There are two forms of analgesic nephropathy, a chronic insidious form of kidney injury that results from repeated consumption of predominantly combination analgesic tablets and an acute kidney injury due to renal vasoconstriction. The risk factors for acute kidney injury are volume depletion, concomitant congestive heart failure, cirrhosis and nephrotic syndrome. Acute kidney injury can occur at any age with 


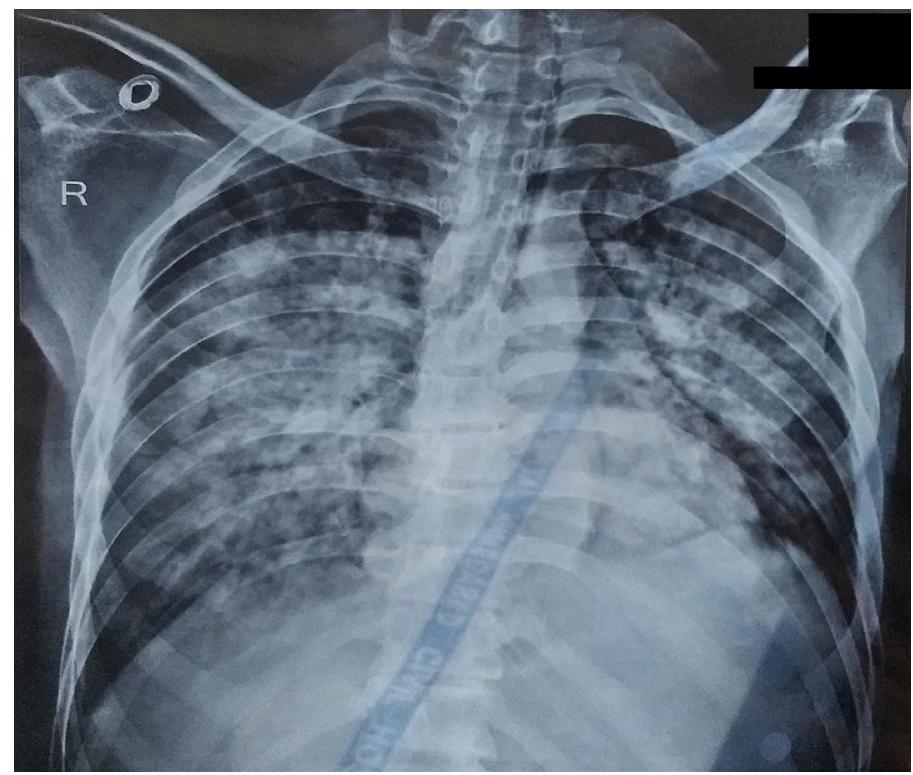

Figure 1: Chest X-Ray of the patient showing bat wing appearance signifying the presence of pulmonary edema. ${ }^{6}$

excessive consumption of NSAIDs, however, it is not associated with reduced kidney size which is characteristically found in chronic kidney disease (CKD). ${ }^{7}$ Analgesics or NSAIDs exert their anti-inflammatory, analgesic and anti-pyretic property by suppression of prostaglandins, which also play a crucial role in renal homeostasis. NSAIDs cause renal damage by causing glomerular injury.

The glomeruli of humans express chemokine's like monocyte chemoattractant protein-1 (MCP-1). This MCP-1 is attributed to the monocyte/ macrophage infiltration into glomeruli and the renal interstitium. ${ }^{8,9}$ Cytokines and growth factors cause meningeal cell proliferation and MCP-1 release, ${ }^{10}$ while Prostaglandin (PGE) ${ }^{11}$ reduces the glomerular MCP-1 expression. Since in glomerulonephritis there is meningeal cell proliferation and monocyte infiltration, it is suggested that endogenously formed prostaglandins have a role in preventing glomerulonephritis. All NSAIDs augment the glomerular production of MCP-1 which plays an important role in glomerular injury. ${ }^{12}$ Increase monocyte and macrophage infiltration were seen in animal models treated with indomethacin signifying the role of prostaglandins in suppressing renal inflammation. ${ }^{13}$ Pro-inflammatory agents like interleukin- $1 \beta^{14}$ and lipopolysaccharide (LPS) ${ }^{15}$ induce PGE2 by COX-2 indicating that COX-2 generated PGE2 plays an important role in suppression of renal inflammatory processes, such as glomerulonephritis. ${ }^{16,17}$ In experimental models it was found that PGE decreases kidney damage through the reduction of glomerular immune complex formation, by reducing inflammatory cell infiltration and deposition of extracellular matrix products. ${ }^{18}$ The experimental study concluded that prostaglandins have a role in the clearing of monocyte/macrophage and the healing process in glomerulonephritis. ${ }^{19,20}$ However, the exact pathophysiological mechanism of analgesic nephropathy especially in acute kidney injury by NSAIDs is not well understood.

The cause of unusually rapid renal failure in this young patient can be possibly due to two causes: the presence of renal amyloidosis, which may have affected renal homeostasis and the use of NSAIDs affecting the protective mechanism of prostaglandins. Further, the patient might have developed left ventricular systolic dysfunction due to acute kidney disease. ${ }^{21}$ This case report suggests that it is prudent to monitor the patients on long term analgesic therapy as rheumatological disorders may themselves cause systemic abnormalities which can increase the likelihood of renal toxicities by NSAIDs.
It is known that NSAIDs do not affect the disease progression of Ankylosing spondylitis and provides symptomatic benefit. However, controlling disease progression by the use of Disease modifying anti rheumatic drugs (DMARDs) is prudent. Judicial use of NSAIDs may help to prevent such occurrences.

\section{ACKNOWLEDGEMENT}

We would like to thank N.M Kaidri for allowing us to evaluate this patient.

\section{CONFLICT OF INTEREST}

The authors declare no conflict of interest.

\section{ABBREVIATIONS}

ESRD: End Stage Renal Disease; NSAID: Non steroidal Anti Inflammatory Drugs; PTH: Parathyroid Hormone; LVEF: Left Ventricular Ejection Fraction; RVSP: Right Ventricular Systolic Pressure; LV: Left Ventricle; AS: Ankylosing Spondylitis; CKD: Chronic Kidney Disease; MCP: Monocyte Chemo attractant; PGE: Prostaglandin E; LPS: Lipopolysacchride; COX: Cyclooxygenase; DMARD: Disease Modifying Anti Rheumatic Dru.

\section{REFERENCES}

1. Saigal R, Agrawal A, Goyal L, Agrawal A, Gupta N. Renal function in Ankylosing Spondylitis. Indian J Rheumatol. 2017:12(3):156. Available from: http://www. indianjrheumatol.com/text.asp?2017/12/3/156/205162

2. Samia B, Hazgui F, Abdelghani KB, Hamida FB, Goucha $R$, Hedri $H$, et al. Renal abnormalities in ankylosing spondylitis. Nephrol Ther. 2012;8(4):220-5.

3. Dönmez S, Pamuk ÖN, Pamuk GE, Aydogdu E, Inman R. Secondary amyloidosis in ankylosing spondylitis. Rheumatol Int. 2013;33(7):1725-9.

4. Kim GH. Renal effects of prostaglandins and cyclooxygenase-2 inhibitors. Electrolyte Blood Press. 2008;6(1):35-41. doi:10.5049/EBP.2008.6.1.35

5. Lourie SH, Denman SJ, Schroeder ET. Association of renal papillary necrosis and ankylosing spondylitis. Arthritis Rheum. 1977;20(4):917-21.

6. Khan AN, Al-Jahdali H, Al-Ghanem S, Gouda A. Reading chest radiographs in the critically ill (Part II): Radiography of lung pathologies common in the ICU patient. Ann Thorac Med. 2009:4(3):149-157. doi:10.4103/1817-1737.53349

7. Faubel S, Patel NU, Lockhart ME, Cadnapaphornchai MA. Renal relevant radiology: use of ultrasonography in patients with AKI. Clin J Am Soc Nephrol. 2014;9(2):382-94. doi:10.2215/CJN.04840513

8. Dember LM. Amyloidosis-associated kidney disease. J Am Soc Nephrol. 2006;17(12):3458-71. doi:10.1681/ASN.2006050460

9. Diamond JR, Kees-Folts D, Ding G, Frye JE, Restrepo NC. Macrophages, monocyte chemoattractant peptide-1 and TGF-beta 1 in experimental hydronephrosis. Am J Physiol. 1994;266(6):F926-33.

10. Prodjosudjadi W, Gerritsma JS, Es LAV, Daha MR, Bruijn JA. Monocyte chemoattractant protein-1 in normal and diseased human kidneys: An immunohistochemical analysis. Clin Nephrol. 1995;44(3):148-55

11. Grandaliano G, Valente AJ, Rozek MM, Abboud HE. Gamma interferon stimulates monocyte chemotactic protein (MCP-1) in human mesangial cells. J Lab Clin Med. 1994;123(2):282-9.

12. Jocks T, Zahner G, Freudenberg J, Wolf G, Thaiss F, Helmchen U, et al Prostaglandin E1 reduces the glomerular mRNA expression of monocytechemoattractant protein 1 in anti-thymocyte antibody-induced glomerular injury. J Am Soc Nephrol. 1996;7(6):897-905

13. Schneider A, Harendza S, Zahner G, Jocks T, Wenzel U, Wolf G, et al. Cyclooxygenase metabolites mediate glomerular monocyte chemoattractant protein-1 formation and monocyte recruitment in experimental glomerulonephritis. Kidney Int. 1999;55(2):430-41.

14. Rzymkiewicz D, Leingang K, Baird N, Morrison AR. Regulation of prostaglandin endoperoxide synthase gene expression in rat mesangial cells by interleukin-1 beta. Am J Physiol. 1994;266(1):F39-45

15. Schneider A, Harendza S, Zahner G, Jocks T, Wenzel U, Wolf G, et al Cyclooxygenase metabolites mediate glomerular monocyte chemoattractant protein-1 formation and monocyte recruitment in experimental glomerulonephritis. Kidney Int. 1999;55(2):430-41.

16. Hirose S, Yamamoto T, Feng L, Yaoita E, Kawasaki K, Goto S, et al. Expression and localization of cyclooxygenase isoforms and cytosolic phospholipase A2 in anti-Thy-1 glomerulonephritis. J Am Soc Nephrol. 1998;9(3):408-16.

17. Blume C, Heise G, Mühlfeld A, Bach D, Schrör K, Gerhardz CD, et al. Effect of flosulide, a selective cyclooxygenase 2 inhibitor, on passive heymann nephritis 
in the rat. Kidney Int. 1999;56(5):1770-8.

18. Hwang D, Jang BC, Yu G, Boudreau M. Expression of mitogen-inducible cyclooxygenase induced by lipopolysaccharide: Mediation through both mitogen- activated protein kinase and NF-kappaB signaling pathways in macrophages. Biochem Pharmacol. 1997;54(1):87-96.

19. Schneider A, Thaiss F, Rau HP, Wolf G, Zahner G, Jocks T, et al. Prostaglandin E1 inhibits collagen expression in anti-thymocyte antibody- induced glomerulonephritis: Possible role of TGF beta. Kidney Int. 1996;50(1):190-9.
20. Zahner G, Schaper M, Panzer U, Kluger M, Stahl RA, Thaiss F, Schneider A. Prostaglandin EP2 and EP4 receptors modulate expression of the chemokine $\mathrm{CCL}_{2}$ (MCP-1) in response to LPS-induced renal glomerular inflammation. Biochem J. 2009;422(3):563-70.

21. Prudhomme M, Coutrot $M$, Michel $T$, et al. Acute Kidney Injury Induces Remote Cardiac Damage and Dysfunction through the Galectin-3 Pathway. JACC Basic TransI Sci. 2019;4(6):717-32. doi:10.1016/j.jacbts.2019.06.005

Article History: Submission Date :05-07-2020 ; Revised Date : 22-07-2020 ; Acceptance Date : 04-08-2020

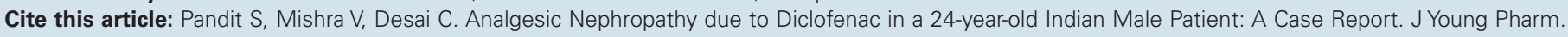
2020;12(3):291-3. 